\title{
EDUCAÇ̃̃O FÍSICA E EDUCAÇÃO INFANTIL: UMA ANÁLISE EM SEIS PERIÓDICOS NACIONAIS
}

\author{
Diego Luz Moura \\ Universidade Federal do Vale do São Francisco, Petrolina, Pernambuco, Brasil \\ Kamilla Ribeiro Nunes Costa \\ Universidade Federal do Vale do São Francisco, Petrolina, Pernambuco, Brasil \\ Marcelo Moreira Antunes \\ Universidade Federal Fluminense, Niterói, Rio de Janeiro, Brasil
}

\begin{abstract}
Resumo
O objetivo do artigo foi analisar a produção da Educação Física sobre a educação infantil em periódicos especializados. A metodologia utilizada foi uma pesquisa bibliográfica em seis periódicos nacionais publicados no período de 2000 a 2012. Foram encontrados 25 artigos. A partir do levantamento foram construídas quatro categorias: diversidade cultural, formação profissional, educação do corpo e planejamento curricular. Ao final percebemos que é necessária uma valorização do movimento corporal, menor ênfase na utilização do movimento como instrumento de disciplinarização e um subsídio que oriente os profissionais de educação física na educação infantil.
\end{abstract}

Palavras-chave: Educação; educação física; educação infantil.

\section{Introdução}

A educação infantil é um tempo e espaço de descobertas e de ampliação das experiências individuais, culturais, sociais e educativas, através da inserção da criança em ambientes distintos dos da família (BASEI, 2008). A Educação Infantil (EI) no Brasil teve origem através das mudanças sociais e econômicas, causadas pela revolução industrial em todo mundo. Inicialmente possuía um caráter assistencialista, com o intuito de ajudar as mulheres de baixa renda que tinham que trabalhar fora de casa. A partir de 1920, a EI começou a se modificar buscando democratização do ensino, pois as creches populares só atendiam as crianças consideradas com necessidades básicas (CAVALARO; MULLER 2009).

A partir de 1930 foi sendo destacada a proteção da criança. O Estado então iniciou a busca de colaborações de órgãos privados, logo nessa mesma época, vem à preocupação com cuidados de saúde e higiene da criança. $\mathrm{O}$ objetivo principal era o combate à mortalidade infantil. O surgimento das creches, jardins de infância e a pré-escola era uma perspectiva emergencial, acreditando que os problemas infantis da sociedade poderiam ser resolvidos através dessas instituições.

Portanto, podemos perceber que historicamente a educação infantil surgiu apenas para atender demandas sociais. Foi apenas na década de 1970 que ocorreu uma valorização da EI através de um olhar pedagógico. É nesse contexto que autores como Wallon, Piaget entre outros começam a produzir reflexões sobre o desenvolvimento da criança no processo de ensino. 
A reorganização da educação veio por meio da nova Lei das Diretrizes e Bases da Educação Nacional (LDB) em 1996, na qual a educação infantil ficou sendo vista como uma fase da pré-escola e logo após a nova LDB passou a fazer parte da educação básica (BRASIL, 1996).

A EI conquistou seu lugar na educação básica e, consequentemente, foi necessária a criação de leis e diretrizes para uma melhor organização dessa etapa educacional. Foi criado o Referencial Curricular Nacional para a Educação Infantil (RCNEI) em 1998, e mais tarde as Diretrizes Curriculares Nacionais para Educação Infantil (DCNEI) em 2009 (BRASIL, 2009).

Podemos perceber que o debate acadêmico sobre a educação infantil é recente, pois se configura como uma área que foi dotada de olhar pedagógico apenas nas últimas décadas. Se o debate no campo educacional é novo, nos parece que o mesmo no campo da Educação Física se torna algo mais contemporâneo ainda, pois foi apenas a partir da década de 1980 que surgiram as primeiras propostas pedagógicas para o campo da educação física escolar.

Outro ponto que remonta a importância de identificar e analisar a produção sobre a educação física na EI, se refere a obrigatoriedade expressa na LDB, onde afirma que a educação física deve-se atuar com esse nível educacional (BRASIL, 1996). Em outras palavras, existem atualmente inúmeros profissionais de educação física atuando em diferentes unidades escolares com a educação física infantil. Todavia, o conhecimento sobre a intervenção neste nível de ensino ainda é pouco conhecido.

Deste modo, é fundamental um levantamento sistemático da produção científica. Destarte, nosso objetivo é analisar a produção do conhecimento sobre a educação física na educação infantil em periódicos especializados produzidos no período de 2000/2012.

\section{Metodologia}

Este estudo apresenta-se como uma pesquisa bibliográfica. Para Rampazzo (2002, p. 53), a pesquisa bibliográfica "procura explicar um problema a partir de referenciais teóricos publicados (em livros, revistas etc.)".

Foi realizado um levantamento em seis periódicos nacionais: Revista Motriz, Revista Movimento, Revista Brasileira de Ciências do Esporte Revista, Revista Brasileira de Educação Física e Esporte ${ }^{1}$, Revista da Educação Física e Pensar a Prática no arco temporal no período de 2000-2012, tendo como critério de inclusão apenas os artigos que tratam especificamente da Educação Física na Educação Infantil.

Selecionamos esses periódicos por se tratarem de revistas com alto nível ${ }^{2}$ de avaliação nos padrões nacionais e por ter em seu foco de publicação, artigos sobre o debate pedagógico do ensino da Educação Física. Entendemos que ao escolher alguns periódicos em detrimento de outros acabamos por selecionar apenas uma parte da produção. Entretanto, não é nosso propósito esgotar o tema, mas apenas levantar tendências da produção a partir de alguns olhares.

O levantamento foi construído em três etapas: 1) realizamos uma leitura dos sumários, buscando selecionar apenas os artigos que se aproximavam do debate da educação física na educação infantil; 2) leitura dos resumos para selecionar os artigos que discutiam especificamente a educação física infantil e; 3) leitura das obras completas.

Encontramos um total de 25 artigos e, a partir da leitura dos textos construímos algumas categorias que ilustram as principais preocupações da educação física sobre a educação infantil. As categorias foram: diversidade cultural, formação profissional, educação do corpo e planejamento curricular.

\footnotetext{
${ }^{1}$ A Revista Brasileira de Educação Física e Esporte era denominada de Revista Paulista de Educação Física até o ano de 2003.

${ }^{2}$ Qualis A2-B2.
} 


\section{A) Diversidade Cultural}

O debate da diversidade cultural se construiu inicialmente para dar voz aos grupos que por hierarquia de poder se viam em relações desiguais. No Brasil foram discutidos em torno de diversos temas como negros, orientação sexual e mulheres entre outros. A diversidade não é um tema de debate específico da educação infantil, mas do debate educacional como um todo. Nos textos analisados verificamos que este debate está relacionado apenas aos temas gênero e inclusão.

O debate sobre gênero teve início no século XX, nos anos de 1970, na busca da igualdade entre homens e mulheres na sociedade. O termo gênero foi utilizado para explicar as diferenças percebidas entre os sexos (SCOTT, 1995). Posto isso, não é negar as características biológicas, mas enfatizar a construção social e histórica produzidas pelas características biológicas.

Esse tema vem chamando a atenção a partir dos anos de 1990, com o intuito de fazer refletir sobre a atuação da escola acerca da separação de sexos no cotidiano escolar (PEREIRA, 2004). Desta forma, o debate no campo educacional possibilitou a necessidade de intervenções para união de meninos e meninas na rotina da escola. A primeira dissertação/tese sobre o tema gênero na educação física escolar foi construída no ano de 1991 (CHANVIANNA; MOURA; MOURÃO, 2010). O que mostra que este debate tem sido presente também no campo da educação física.

O debate de gênero tem se configurado como tema de preocupação para a educação infantil. No levantamento encontramos três artigos sobre o tema gênero: (SAYÃO, 2002a; SILVA; DAOLIO, 2007; FALKEMBACH; DREXSLER; WERLE, 2006).

$O$ debate de gênero foi transladado para o campo acadêmico ainda com muita força proveniente do campo político. De acordo com Silva e Daolio (2007), a crescente visibilidade do movimento e da teorização feminista forçou as perspectivas críticas a conceder importância sobre as relações de gênero. O pressuposto é de que há uma profunda desigualdade entre homens e mulheres.

Ao analisar os artigos podemos perceber que a argumentação é muito próxima ao debate de gênero em outros níveis de ensino. Sayão (2002a) e Silva e Daolio (2007) apontam que desde a idade da educação infantil é possível identificar uma tendência pela separação entre meninos e meninas nas aulas de educação física.

$\mathrm{Na}$ maioria das vezes, as meninas agrupam-se entre si e escolhem brincadeiras relacionadas ao que denominamos tradicionalmente universo feminino: brincam de bonecas, de casinha, de cabeleireiro. Enquanto isso, os meninos fazem uso de jogos como memória, "lego" ou de construção e outros similares. Em alguns casos, meninos e meninas interagem, porém, na maioria das vezes, fazem opções por atividades com crianças do mesmo sexo (SAYÃO, 2002a, p.7).

Podemos verificar que os autores ao descreverem o fenômeno da separação por gênero realizam uma análise com menor ênfase nas discussões políticas. Diferente das teses e dissertações produzidas no campo da educação física escolar. Chan-Vianna, Moura e Mourão (2010), analisando essa produção do período de 1990/2005, apontam que as teses e dissertações analisadas partem da existência do sexismo e discriminação nas aulas de educação física. Apontam que pesquisas buscam mais ratificar um ponto de vista concebido do que buscar indicadores. Nessa pesquisa, observamos que os autores realizam um maior estranhamento em relação ao objeto de estudo.

Falkembach, Drexsler e Werle (2006) apontam que a separação de meninas e meninos nas aulas de educação física está mais relacionada com a diferença de habilidades motrizes e 
menos com questões culturais. No mesmo sentido, Chan-Vianna, Moura e Mourão (2010) apontam que a categoria gênero não pode ser entendida como principal característica da inclusão e exclusão de alunos. Na medida em que a habilidade esportiva é principal meio de participação nas aulas.

Para solução desse debate Sayão (2002a), Silva e Daolio (2007) e Falkembach, Drexsler e Werle (2006) apontam que a principal solução seria a integração de meninos e meninas. Acreditamos que a integração é um instrumento interessante, mas não pode ser compreendido de uma forma determinista ao correr o risco de acreditarmos que qualquer divisão poderia ser considerada sexismo. O principal para o debate de gênero é a reflexão sobre os processos de discriminação (SILVA, 2006). Os autores apontam a necessidade de discussão do tema. Entretanto, tal estratégia fica secundarizada em relação à proposta de colocar juntos meninos e meninas.

O debate sobre a inclusão de pessoas com deficiência ganhou destaque no discurso da educação brasileira na década de 1990 (SILVA, 2010). Uma das principais repercussões se deu pela assinatura da declaração de Salamanca (1994). Tal documento reafirmou o compromisso de valorização da educação especial. Portanto,o debate sobre inclusão de alunos com deficiência tem sido consensual entre diferentes documentos e autores.

Para Lei de Diretrizes e Bases da Educação Brasileira (BRASIL, 1996), os alunos com alguma deficiência têm o direito de acessar a rede de ensino a partir da educação especial, com objetivo de uma possível inclusão desses educandos posteriormente. Os Parâmetros Curriculares Nacionais (BRASIL, 1997) apontam que a inclusão é um desafio ao sistema de ensino e requer planejamento e organização que deem conta dessa diversidade, buscando alternativas e adaptações quando for necessário para o ensino e aprendizagem do aluno. Segundo Silva (2010), esse documento "traduz a proposta da escola inclusiva para os deficientes ao sinalizar que, as respostas às necessidades pedagógicas de todos os alunos devem ser realizadas no mesmo contexto por meio de atividades comuns, embora adaptadas" (p. 220).

Em contraponto, Falkembach et al. (2007) afirmam que essa educação levou ao isolamento desses alunos, confirmando a ideia de que não se deve conviver juntos. Falkembach et al. (2007) chamam a atenção a esse debate na educação infantil, pois a aula de Educação Física pode favorecer a construção de uma nova atitude com relação a deficiência. Afirma que haverá sempre exclusão enquanto a ação pedagógica da educação física for apenas ao ensino do movimento e desenvolvimento de técnicas.

De fato, metodologias equivocadas podem ser uma barreira para uma educação que vise à participação de todos. Acreditamos que a participação de alunos com deficiência nas aulas de Educação Física constitui como grande benefício para todos os alunos no seu desenvolvimento, além de favorecer o aprendizado, a socialização e o respeito às limitações do outro. E que estratégias devem ser feitas para uma melhor inclusão e convívio desses alunos.

\section{B) Formação Profissional}

O tema da formação profissional do professor de Educação Física na Educação Infantil é debatido em sete artigos: (FERRAZ; MACEDO, 2001a;b; PINTO, 2001; BARBOSA, 2002; SAYÃO, 2002b; RODRIGUES; FIGUEIREDO, 2011; NUNES; FERREIRA NETO, 2011). Os artigos analisados refletem os diferentes momentos pelos quais a educação infantil passou no Brasil, pois foi apenas com a Lei 10.328 de 2001 que forneceu nova redação à Lei de Diretrizes e Bases da Educação Nacional (LDB), dando um caráter de obrigatoriedade à Educação Física em toda a educação básica. 
Segundo o Referencial Curricular Nacional da Educação Infantil (RCNEI) (BRASIL, 1998), ainda há uma quantidade significativa de profissionais que não possuem uma preparação adequada. O RCNEI aponta que esses professores devem possuir um perfil diferenciado das demais etapas da educação básica, tendo a diversidade de conhecimento um fator precípuo. Aponta que deve ser feita uma reestruturação nessas escolas para que esse profissional possa obter melhor preparo e formação. Entretanto, nem todos os Municípios inseriram a Educação Física na educação infantil. Neste sentido, os artigos discutem tanto o perfil que se quer como o que se encontra nas escolas.

Os artigos discutem a necessidade da construção de uma identidade do profissional de educação física na educação infantil e a inserção do debate da educação infantil nos cursos de graduação em Educação Física.

Rodrigues e Figueiredo (2011) mostram que atualmente esse professor busca sua identidade profissional na educação infantil que ainda não foi definida. De acordo com os autores isso ocorre porque não há uma clareza sobre as formas de atuação na educação infantil. Nesse sentido, Nunes e Ferreira Neto (2011), a partir de uma pesquisa com uma professora, apontam que a insegurança em intervir na educação infantil é um elemento constante no início do trabalho dos professores. Já para Sayão (2002b) isso acontece por falta de conhecimento e preparação na formação desses docentes.

Apesar de a percepção da questão da formação se apresentar urgente na atualidade, para Saviani (2009) o problema já se constitui desde o século XIX, e pode-se afirmar que ele é mais antigo ainda. Entretanto é no século XIX que surge a necessidade de universalização da educação e consequentemente os sistemas nacionais de ensino surgem. E é nesse contexto que a padronização da formação se institui, o que dificulta o desenvolvimento de especificidades necessárias às novas demandas que surgem no campo educacional.

Notemos que a falta segurança ou incapacidade momentânea é uma característica normal em relação a situações novas que enfrentamos no cotidiano. A principal solução encontrada pelos autores é a inserção da Educação Infantil nos cursos de graduação em Educação Física. Pinto (2001) argumenta que a discussão sobre a educação infantil não é comum na preparação nos cursos de graduação, o foco da discussão se encontra nos níveis posteriores à educação infantil, especialmente a partir da segunda fase do ensino fundamental. Por outro lado, Barbosa (2002) aponta que há um novo olhar nos cursos de licenciatura para a formação dos futuros professores que atuem na educação infantil. Os cursos vêm se reestruturando para incluir a educação infantil em seus eixos de discussão e de aprofundamento curricular. Entretanto, Gatti (2002) afirma que nos cursos de licenciatura não há uma efetiva interação entre os conteúdos específicos e os conteúdos pedagógicos, o que cria uma barreira na formação para a atuação pedagógica.

A preocupação com a formação profissional dos professores de Educação Física está presente em alguns artigos (FERRAZ; MACEDO, 2001a; RODRIGUES, FIGUEIREDO 2011; NUNES, FERREIRA NETO, 2011). Portanto, a busca para uma melhor forma de esse profissional lidar com as crianças ainda não está definida. Pinto (2001) aponta que a intervenção em educação infantil é um desafio, pois amplifica o problema da falta de especificidade tão debatido nos níveis de ensino superiores. Em contraponto, Lacerda e Costa (2012) mostram que atuar apenas com as habilidades motoras não seria a melhor maneira de trabalhar com essas crianças e que a melhor solução seria atuar com outras dimensões do conteúdo.

Barbosa (2002) afirma que há uma falta de investimento nos cursos de licenciatura, o que contribuiu para uma má formação e atuação. Sayão (2002b) sugere na formação desses profissionais o reconhecimento do corpo e suas reações, como um fator de auxílio ao atuarem com essas crianças. 
Para tal, nos processos de formação das profissionais que atuam com as crianças pequenas, faz-se necessário incluir o olhar para nós mesmas, é preciso aprender a conhecer as reações de nossos corpos ao toque, à música, aos odores (SAYÃO, 2002b p.62).

O debate dos autores aponta no sentido de demarcar a necessidade da construção de uma identidade profissional, pois o professor de Educação Física é visto como o "tio da brincadeira" (RODRIGUES; FIGUEIREDO, 2011) ou um dinamizador (NUNES; FERREIRA NETO, 2011).

Segundo Ferraz e Macedo (2001a), Barbosa (2002) e Sayão (2002b), é importante a preparação prática específica dos futuros professores para a intervenção com crianças de zero a seis anos. Segundo Rodrigues (1998), o professor deve mostrar para o aluno o porquê de ele estar realizando aquele movimento, não deixá-lo entender que é apenas o fazer por fazer. De acordo com Rodrigues (1998), dessa forma as aulas de Educação Física se tornariam mais consolidadas nas escolas. Pinto (2001) mostra que os professores estão utilizando como escape a ação corporal com fim em si próprio, entretanto transmitir reflexões e críticas através dessas ações é uma das funções que esses profissionais devem passar para seus alunos. $\mathrm{Na}$ concepção desses autores, enquanto os professores não perceberem a educação física para além do movimento pelo movimento serão vistos apenas como recreadores.

Ferraz e Macedo (2001ab) apontam a necessidade urgente de um projeto de formação continuada e acompanhamento pedagógico para os professores de Educação Física que atuam na educação infantil.

\section{C) Educação do Corpo}

Essa categoria é a que possui maior incidência nos artigos analisados. Do total de 21, 17 questionam a forma com que o movimento é trabalhado nesse nível de ensino (GARANHANI, 2002; SAYÃO，2002b; SILVA; PINHEIRO， 2002; SOARES，2002; AYOUB, 2005; FERRAZ; FLORES, 2004; RICHTER; VAZ, 2005; SILVA, 2005; ANDRADE FILHO et al., 2006; FALKEMBACH et al., 2006; FALKEMBACH et al., 2007; FREIRE; SANTANA, 2007; SILVA; DAOLIO, 2007; KAWANISHI; AMARAL, 2008; UCHÔGA; PRODÓCIMO, 2008; PALMA; PEREIRA; VALENTINI, 2009; SANTOS; LIMA, 2009; FARIA et al., 2010;NUNES; FERREIRA NETO, 2011).

Analisando os artigos, percebemos um paradoxo relacionado com a educação do corpo na educação infantil: por um lado é um instrumento de aprendizagem, mas por outro uma forma de disciplinarização. A educação através do corpo é apontada como elemento fundamental em nossa sociedade (ALBUQUERQUE, 2001). Na questão da disciplinarização, Elias (1990) nos apresenta a educação do corpo e o processo civilizador da sociedade como elementos constituintes do mesmo mecanismo de controle dos comportamentos sociais. Assim, esse mesmo corpo que aprende, é também uma construção a partir de influências culturalmente socializadas.

O movimento é a principal característica da criança, é através dele que a criança pode se expressar, aprender e se desenvolver. Sua presença no cotidiano escolar é indispensável, pois o movimento corporal se torna uma forma de linguagem da criança, através dele as crianças constroem conhecimento.

Logo se torna a matriz básica para educação infantil, porque através do movimento ela pode se compreender, expressar os significados presentes em seu contexto além de auxiliar em sua autonomia e na socialização.

Pensar o corpo e movimento na educação infantil é considerar que esta é a maneira que a criança aprende e se relaciona com o mundo a sua volta, bem como o modo 
como se apropria e ressignifica a cultura na qual está inserida (UCHÔGA; PRODÓCIMO, 2008 p.1).

As aulas de educação física na educação infantil é uma das primeiras formas de vivenciar o movimento de modo mais sistemático e mediado por objetivos (FALKEMBACH et al., 2006). De fato, a inserção de uma intervenção lúdica nas aulas de educação física é uma característica consensual na área da educação e da educação física. Tal aspecto é reforçado nos artigos analisados.

Através do brincar, movimentando-se, a criança explora, descobre, aprende, conhece a si e ao outro, experimenta situações diferentes; enfim, por meio de vivências lúdicas é que a criança é plenamente criança (FARIA et al., 2010, p.125).

Podemos observar que os autores apontam o jogo como uma forma de que o brincar é externalizado. Essa ideia está presente nos autores da educação, educação física e nos documentos oficiais que versam sobre o ensino da educação infantil. É consenso que o brincar é um elemento indispensável no cotidiano da educação infantil. E está incluído, inclusive, nas Diretrizes Curriculares Nacionais da Educação Infantil (BRASIL, 2009, art 8º p. 2): “[...] garantir à criança acesso a processos de apropriação, renovação e articulação de conhecimentos e aprendizagens de diferentes linguagens, assim como o direito à proteção, à saúde, à liberdade, à confiança, ao respeito, à dignidade, à brincadeira, à convivência e à interação com outras crianças". Logo o brincar se torna precípuo nos debates e os pesquisadores apontam os benefícios dessa atividade para a criança.

Conforme vimos, o brincar se torna uma forma de construir aprendizado pelo seu caráter lúdico que é apreciado pelas crianças. Todavia, esse caráter lúdico tem se focado apenas nas aulas de educação física e nos tempos de recreação. Se observarmos atentamente, percebemos que há na educação infantil uma rotina rígida em que existe tempo para tudo inclusive para movimentar-se (UCHÔGA, 2008; FARIA 2010).

Porém, nem sempre o brincar se torna uma ação pedagógica para o aprendizado infantil, sabemos que o brincar é a principal ação infantil e acaba transformando-o como um instrumento para a disciplinarização da criança. Segundo Nóbrega (2005), o movimento não deve ser utilizado apena como acessório na formação do indivíduo, pois o ser humano é um corpo, e este deve ser entendido além de sua instrumentalidade.

Apesar de a bibliografia recente apontar para uma educação de 0 a 6 anos voltada para a criança, e não para o aluno, os momentos mostram que a tentativa já é de escolarizar este corpo, no sentido de colocá-lo dentro dos "padrões" que a educação escolar se apresenta Hoje. (UCHÔGA; PADRÓCIMO, 2008 p. 227).

Há uma escolarização do corpo no sentido de colocá-los em determinado padrão, levando a educação física um momento de liberdade corporal, o espaço em que a criança pode ser "livre" para movimentar-se. O movimento se torna uma moeda de troca, que é utilizada para barganhar punição ou prêmio (STRAZZACAPPA, 2001).

Nas escolas de educação infantil existem rotinas e horários a serem cumpridos. O que limita a fruição corporal. Segundo Focault (1999), isso acontece porque a disciplina é um dos definidores da modernidade e funciona distribuindo os indivíduos no espaço. $\mathrm{O}$ autor aponta que o controle do tempo, a vigilância hierárquica, a sanção normalizadora e a avaliação são estratégias utilizadas para o funcionamento dessa disciplina (LEMOS, 2007). Logo, essas estratégias não estão incluídas apenas nas escolas, mas também em outras instituições da sociedade, como a prisão, o quartel e os hospitais. Como a escola de educação infantil é vista para o cuidado e educação da criança, o brincar tornou-se a principal maneira de controlar ou 
docilizar os corpos. Focault (1999) chama de "corpos dóceis" o resultado do processo de docilização dos corpos.

Contudo, Richter e Vaz (2005) entendem que esse tempo e espaço devem ser recriados para uma melhor educação. Nunes (2011) e Sayão (2002b) mostram que a utilização de diferentes espaços também é importante na construção infantil.

Esses artigos apontam a necessidade de uma valorização do movimento na educação infantil e um menor controle disciplinar sobre este. Para isto, sugerem que os professores utilizem o movimento em sua totalidade, não visando apenas às habilidades motoras.

\section{D) Planejamento Pedagógico}

A obrigatoriedade da educação física na educação infantil promoveu uma série de tensões sobre o que ensinar neste nível de ensino. No meio da falta de subsídios que orientem o professor, observamos alguns planejamentos pedagógicos em: (SOARES, 2002; GARANHANI, 2002; SILVA, 2005; AYOUB, 2005; KAWANISHI; AMARAL, 2008). Podemos notar que mesmo sem uma sistematização mais explícita e um embasamento teórico definido, tais estratégias possibilitam repensar em alguns pontos a intervenção da educação física na educação infantil.

Os autores identificam que a prática da educação física na educação infantil encontrase no cotidiano escolar através de três formas de intervenção: aquela focada na psicomotricidade, no desenvolvimento motor e na ludicidade.

De fato, tais perspectivas teóricas influenciaram um novo modelo de educação física (DARIDO 2003). Segundo Moura (2012), essas abordagens surgiram na tentativa de ampliar a forma de intervenção para aquele focada apenas no esporte.

Os artigos analisados apontam que há uma falta de subsídio para as aulas de Educação Física, limitando a contribuição que essa disciplina pode levar para a criança. Logo se torna importante a realização de propostas que possam orientar aos professores neste nível de ensino.

Verificamos duas formas de inserção da Educação Física na Educação Infantil apresentada pelos autores com características e ações pedagógicas diferentes. A primeira proposta foi o planejamento através de projetos pedagógicos sugeridos por Soares (2002) e Ayoub (2005). Soares (2002) sugere a participação dos professores, pais, coordenadores e a direção da instituição na construção da prática pedagógica. Ayoub (2005) acredita que o projeto pedagógico possibilita o desenvolvimento da criança na totalidade. Sugere como eixo central de ensino os temas da cultura corporal (jogo, luta, ginástica, dança e esporte). De acordo com o autor, a educação física deve incluir em suas aulas a roda de conversa.

A busca por uma organização curricular na escola infantil possui uma preocupação dos autores em que buscam formas para que isso seja realizado. Silva (2005), Garanhani (2002) e Kawanishi e Amaral(2008) sugerem algumas ações para que a educação física possa se tornar uma disciplina inserida no currículo pedagógico das escolas infantis.

Silva (2005) ressalta que a educação física faça parte do currículo da educação infantil. Apresenta a necessidade de construção de temas, conteúdos e uma avaliação que leve a criança a entender seu papel no mundo. Aponta como conteúdo, os temas da cultura corporal (jogos/brincadeiras populares, danças, capoeira e a ginástica), tendo como atividades estruturantes na construção cultural de cada um deles os jogos e as brincadeiras.

Garanhani (2002) propõe uma orientação curricular para educação infantil onde a educação física através do movimento possa transmitir o desenvolvimento físico-motor e a compreensão, expressão e comunicação da criança em seu contexto sócio cultural. Apresenta três eixos em que a organização do tempo, a seleção de atividades pedagógicas e as atividades básicas dos professores devem se adequar. Os três eixos são: autonomia e identidade corporal, 
socialização e; aplicação do conhecimento das práticas infantis. E determina o brincar como princípio pedagógico, através dos jogos e brincadeiras.

Kawanishi e Amaral (2008) apresentam uma proposta onde marca as características da educação física na educação infantil que devem superar, entretanto não apresenta uma proposta que possa instrumentalizar os professores no cotidiano escolar. Os autores sugerem uma prática pedagógica em que os professores possam levar a criança a tornar um ser humano crítico.

Analisando esses planejamentos curriculares observamos que todos os autores buscam uma maneira para que a Educação Física possa se tornar uma disciplina significativa na educação infantil. Há um consenso dos autores ao definir como conteúdo os temas da cultura corporal (jogo,dança, luta e esporte) e o princípio de base para aplicar esses conteúdos à atividade lúdica e o brincar. Entretanto, os autores apresentam suas propostas, mas apenas Ayoub (2005) aplicou sua proposta no âmbito escolar.

É necessário que mais propostas possam ser realizadas e aplicadas para que esse objetivo possa ser alcançado, pois percebemos que um material didático que auxilie os professores de educação física neste nível de ensino contribuirá para a formação integral do aluno e a consolidação da educação física na educação infantil.

\title{
Considerações finais
}

Podemos perceber que há pouca produção sobre a educação física infantil no período pesquisado. Faltam subsídios que auxiliem a intervenção da educação física na educação infantil. Os artigos embora reconheçam a dificuldade de atuar neste nível de ensino não indicam uma orientação ou proposta de intervenção. A discussão acaba ficando presa à reafirmação da importância da educação física no currículo, quer seja inserindo sua importância pedagógica, quer seja discutindo questões de gênero ou deficiência.

Essa falta de subsídios por um lado é consequência de três aspectos que estão intrincados: a obrigatoriedade das aulas de educação física na educação infantil é relativamente recente, pois somente no ano de $2003^{3}$ e os cursos de graduação ainda não focam na educação física infantil quando comparada aos demais níveis de ensino.

Os artigos compreendem o movimento corporal como elemento fundamental da intervenção com a educação infantil. Ressaltam que deveria haver uma maior valorização do movimento e uma diminuição no controle do corpo sobre este, pois a disciplinarização do corpo parece ser característica e uma das principais formas de utilização do movimento na escola.

Acreditamos que a produção de um subsídio teórico poderia ser o primeiro passo para a construção de uma nova forma de entender e intervir na educação física infantil.

\section{PHYSICAL EDUCATION AND CHILDHOOD EDUCATION: AN ANALYSIS IN SIX BRAZILIAN JOURNALS}

\begin{abstract}
The study aimed at analyzing the production of Physical Education about the childhood education in specialized journals between 2000 and 2012. The methodology used was a bibliographical research in six national journals in the period of 2000-2012. 25 articles have been found. Based on these articles were built four categories: cultural diversity, professional
\end{abstract}

${ }^{3}$ Lei $n^{\circ} 10.793$ de 2003. 
formation, body education and curriculum planning. At the end we realize that is required a valuation of body movement, lesser emphasis on the use of the movement as an instrument of discipline and a subsidy which guides the physical education teachers in early childhood education.

Keywords: Education; physical education; childhood education.

\section{EDUCACIÓN FÍSICA Y EDUCACIÓN DE LA PRIMERA INFANCIA: UN ANÁLISIS EN SEIS REVISTAS NACIONALES}

\section{Resumen}

El objetivo del artículo fue analizar la producción de la Educación Física sobre la educación infantil en revistas especializadas. La metodología utilizada fue una investigación bibliográfica en seis periódicos nacionales publicados en el período de 2000 hasta 2012. Fueron encontrados 25 artículos. A partir del levantamiento fueron construidas cuatro categorías: la diversidad cultural, la formación profesional, educación del cuerpo y planificación del currículo. Al final nos dimos cuenta que se requiere una valoración del movimiento del cuerpo, menor énfasis en el uso del movimiento como herramienta de disciplinalización y un subsidio que guíe a los profesionales de educación física en la educación infantil.

Palabras clave: Educación; educación física; educación para la primera infancia.

\section{Referências}

ALBUQUERQUE, L. M. B. As invenções do corpo: modernidade e contra modernidade. Motriz, Rio Claro. v.7, n.1, p.33-39, jan./jun. 2001.

ANDRADE FILHO, N. F; SILVA, R. L; FIGUEIREDO, Z. C. C. O brincar/jogar como fenômeno transicional na construção da autonomia e da identidade da criança de zero a seis anos. Rev. Bras. Cienc. Esporte, Campinas, v. 27, n. 2, 2006. p.75-90.

AYOUB, E. Reflexões sobre a educação física na educação infantil. Rev. Pau. Edu. Fís., São Paulo, supl. 4, 2001. p.53-60.

Narrando experiências com a educação física na educação infantil. Revista Brasileira de Ciências do Esporte: Campinas, v.26, n.3, 2005. p.143-158.

BARBOSA, I. G. Educação Infantil: O lugar da pedagogia e da educação física em uma perspectiva sócio-histórico-dialética. Pensar a Prática, Goiânia, n.5, 2002. p.71-91.

BASEI, A. P. A educação física na educação infantil: a importância do movimentar-se e suas contribuições no desenvolvimento da criança. Rev. Iberoamericana de Educacion, Santa Maria, n. 47/3, out., 2008.

BRASIL. Declaração de Salamanca e linha de ação sobre necessidades educativas especiais. Brasília: CORDE. 1994.

Ministério da Educação e Cultura. Lei de Diretrizes e Bases da Educação Nacional. Lei $\mathrm{n}^{\circ}$ 9394, de 20 de dezembro de 1996. Dispõe sobre as Diretrizes e Bases da Educação Nacional. Brasília, DF: MEC, 1996. 
Ministério da Educação e do Desporto. Parâmetros Curriculares Nacionais. Brasília: MEC/SEF, 1997.

- Secretaria de Educação Fundamental. Referencial Curricular Nacional para a Educação Infantil. Brasília, v. 1, 1998.

. Lei $\mathbf{n}^{\mathbf{0}}$. 11.114, de 9 de maio de 2005. Altera os arts. 6º 30, 32 e 87 da Lei nº 9.394 , de 20 de dezembro de 1996, com o objetivo de tornar obrigatório o início do ensino fundamental aos seis anos de idade.

Ministério da Educação. Conselho Nacional de Educação. Fixa as Diretrizes curriculares nacionais para a Educação Infantil; Resolução n. 5, de 17/12/2009, Brasília: MEC, 2009.

CHAN-VIANNA, A. J; MOURA, D; MOURÃO, L. Educação Física, gênero e escola: uma análise da produção acadêmica. Movimento, Porto Alegre, v. 16, n. 02, 2010. p. 149-164.

CAVAlARO, A. G.; MULlER, V. R. Educação Física na Educação Física na Educação Infantil: uma realidade almejada. Revista Educar, Curitiba, n. 34, 2009. p. 241-250.

DARIDO, S. C. Educação física na escola: questões e reflexões. Rio de janeiro: Guanabara Koogan, 2003.

DARIDO, S. C.; IMPOLCETTO, F. M; et al. A. Livro didático na Educação Física Escolar: considerações iniciais. Motriz, Rio Claro, v.16, n.2, 2010. p. 450-457.

ELIAS, N. O processo civilizador: uma história dos costumes. Rio de Janeiro: Zahar, 1990.

FALKEMBACH, A. P; DREXSLER, G; WERLE, V. Investigando a ação pedagógica da educação física na educação infantil. Movimento, Porto alegre, v.12, n.01, 2006. p. 81-103.

FALKENBACH, A. P; et al. A inclusão de crianças com necessidades especiais nas aulas de Educação Física na educação infantil. Movimento, Porto Alegre, v.13, n. 02, 2007. p. 37-53.

FARIA, M. C. M; et al. .Atividades motoras cotidianas e suas influências no desenvolvimento de pré-escolares. Revista Movimento, Porto Alegre, v. 16, n. 01, 2010. p. 113-130.

FERRAZ, O. L; MACEDO, L. Reflexões sobre a Educação Física na educação infantil incluindo o referencial curricular nacional. Revista Paulista de Educação Física. São Paulo, v.15, n.1, 2001a. p. 83-102.

; __ Educação física infantil no município de São Paulo: diagnostico e representação curricular em professores. Revista Paulista de Educação Física, São Paulo, v.15, n.1, 2001b. p.63-82.

FERRAZ, O. L; FLORES, K. Z. Educação Física na educação infantil: influência de um programa na aprendizagem e desenvolvimento de conteúdos conceituais e procedimentais. Revista Brasileira de Educação Física e Esporte, São Paulo, v.18, n.1, 2004. p. 47-60. 
FERRAZ, O. L; CORREIA, W. R. Teorias curriculares, perspectivas teóricas em Educação Física Escolar e implicações para a formação docente. Revista Brasileira de Ciências do Esporte, São Paulo, v.26, n.3, p.531-40, jul./set. 2012.

FOUCAULT, M. Vigiar e punir: o nascimento da prisão. Tradução R. Ramalhete. 21.ed. Petrópolis:Vozes, 1999.

FREIRE, J. B.; SANTANA, G. M. L. Relações sociais no desenvolvimento da imaginação por meio de jogos. Motriz, Rio Claro, v.13 n.4, 2007. p. 249-258.

GATTI, B. A. Formação de professores e carreira: problemas e movimentos de renovação. 2.ed. Campinas: Autores Associados, 2002.

GARANHANI, M. C. A educação física na escolarização da pequena infância. Pensar a Prática, Goiânia,n,5, 2002. p. 106-122.

KAWANISHI, M. M.; AMARAL, S. C. F. Concepções da educação do corpo em instituições de educação infantil em Campinas. Revista Motriz, Rio Claro, v.14 n.2 p.135-147, abr./jun. 2008 .

KRAMER, S. A Política do Pré-escolar no Brasil: a arte do disfarce. São Paulo: Cortez, 1995.

LACERDA, C. G; COSTA, M. B. Educação Física na Educação Infantil e o Currículo da Formação Inicial. Revista Brasileira de Ciências do Esporte, Florianópolis, v. 34, n. 2, 2012. p. 327-341.

LEMOS, F. C. S. A apropriação do brincar como instrumento de disciplina e controle das crianças. Estudos e Pesquisas em Psicologia, UERJ, RJ, ano 7, n. 1, 2007. $1^{\circ}$ semestre.

PALMA, M. S; PEREIRA, B; VALENTINI, N. C. Jogo com orientação: uma proposta metodológica para a educação física escolar. Revista da Educação Física, Maringá, v.20, n.4, 2009. p. 529-541.

MOURA, D. L. Cultura e educação física escolar: da teoria à pratica. São Paulo: Phorte, 2012.

NÓBREGA, T P. Qual o Lugar do Corpo na Educação? Notas sobre conhecimento, processos cognitivos e currículo. Educ. Soc., Campinas, vol. 26, n. 91, 2005. p. 599-615.

NUNES, K. R; FERREIRA NETO, A. Saberes e Fazeres praticados nos cotidianos da educação física na educação infantil. Pensar a Prática, Goiânia, v. 14, n. 1, 2011. p. 1-10.

PEREIRA, S. A. M. O sexismo nas aulas de educação física: uma análise dos desenhos infantis e dos estereótipos de gênero nos jogos e brincadeiras. Tese (Doutorado em Educação Física) - Universidade Gama Filho, Rio de Janeiro, 2004.

PINTO, R. M. N. A formação de professores para a educação infantil: Desafios para a universidade. Revista Pensar a Prática, Goiânia, n.4, 2001. p. 135-148. 
RAMPAZZO, L. Metodologia científica: para os alunos dos cursos de graduação e pósgraduação. 3. ed. São Paulo: Loyola, 2002.

RICHTER, A. C; VAZ, A. F. Corpos, saberes e infância: um inventário para estudos sobre educação do corpo em ambientes educacionais de 0 a 6 anos. Revista Brasileira de Ciências do Esporte, São Paulo, v. 26, n.3, 2005. p. 79-93.

RODRIGUES, A. T. A questão da formação de professores de Educação Física e a concepção de professor enquanto intelectual-reflexivo-transformador. Revista Pensar a Prática, Goiânia,v. 1, 1998. p. 47-58.

RODRIGUES, C.; FREITAS, D. Educação física e educação infantil: uma reflexão teórica. Diálogos possíveis. jan/jun., 2008. Disponível em: < www.fsba.edu.br/dialogospossiveis>. Acesso em: 25 jan. 2015.

RODRIGUES, R. M; FIGUEIREDO, Z. C. Construção identitária da professora de Educação Física em uma instituição de educação infantil. Revista Movimento, Porto Alegre, v. 17, n. 04, 2011. p. 65-81.

ROSEMBERG, D. S.O processo de formação continuada de professores universitários: do instituído ao instituíste. Rio de Janeiro: Wak Editora, 2002.

SAVIANI, D. Formação de professores: aspectos históricos e teóricos do problema no contexto brasileiro. Revista Brasileira de Educação, Campinas, v.14, n.40, jan./abr. 2009. p.143-155.

SAYÃO, D. T. A hora de... Educação Física na pré-escola. Anais do X Conbrace, Goiânia, v. 1, 1997. p. 261-268.

A Construção de identidades e papéis de gênero na infância: articulando temas para pensar o trabalho pedagógico da educação física na educação infantil. Pensar a Prática, Goiânia, n.5, jul./jun, 2002a, p.1-14.

Corpo e movimento: notas relacionadas para problematizar algumas questões relacionadas à Educação Infantil e à Educação Física. Revista Brasileira de Ciências do Esporte, Campinas, v. 23, n.2, p.55-67, 2002b.

SANTOS, E. G; LIMA, J. M. A ação pedagógica sob a perspectiva de Henri Wallon. Motriz, Rio Claro, v.15, n.2, p.340-348, 2009.

SCOTT, J. Gênero: uma categoria útil de análise histórica. Educação \& Realidade. Porto Alegre, v. 20, n. 2, jul./dez. 1995, p. 71-99.

SILVA, A. M.; DAOLIO, J. Análise etnográfica das relações de gênero em brincadeiras realizadas por um grupo de crianças de pré-escola: contribuições para uma pesquisa em busca dos significados. Revista Movimento, Porto Alegre, v.13, n. 01, p.13-37, jan./abr. 2007.

SILVA, E. F; PINHEIRO, M. C. M. A Educação Infantil como campo de conhecimento e suas possíveis interfaces com a Educação Física. Revista Pensar a Prática, Goiânia, 5: 3957, jul./jun. 2001-2002. 
SILVA, E. J. S. A educação física como componente curricular na educação infantil: elementos para uma proposta de ensino. Revista Brasileira de Ciências do Esporte, Campinas, v.26, n.3, p.127-142, 2005.

SILVA, F. C. T. Entre o processo civilizador e a gestão controlada do currículo: a escola inclusiva "dos deficientes". Currículo sem Fronteiras, Mato Grosso do Sul, v. 10, p. 214227, 2010.

SILVA, J. V. P. Crescimento, habilidades motoras básicas e cotidiano infantil de crianças de Campo Grande - MS.2006. Dissertação (Mestrado) - Curso de Educação Física, UNIMEP, Piracicaba, 2006.

SOARES, A. F. Os Projetos de Ensino e a Educação Física na Educação Infantil. Pensar a Prática, Goiânia, 5: 15-38, Jul./Jun. 2001-2002.

STRAZZACAPPA, M. A Educação e a Fábrica de Corpos: a dança na escola. Cadernos Cedes, ano XXI, n. 53, abr.2001.

UCHÔGA, L. A. R; PRODÓCIMO, E. Corpo e movimento na educação infantil. Revista Motriz, Rio Claro, v.14, n.3, p.222-232, 2008.

Recebido em: 20/02/2015

Revisado em: 14/09/2015

Aprovado em: 10/11/2015

Endereço para correspondência:

lightdiego@yahoo.com.br

Diego Luz Moura

Universidade Federal do Vale do São Francisco

CEFIS - Educação Física.

Avenida José de Sá Maniçoba

Centro

56304-205 - Petrolina, PE - Brasil 